\title{
The use of information technology for international transfer pricing in multinational enterprises
}

\section{By: Lars Hemling, J. Christian Plesner Rossing and Andreas Hoffjan}

\begin{abstract}
This paper studies the degree to which multinational enterprises (MNEs) use information technology (IT) for automating international transfer pricing (ITP). Based on 21 interviews conducted with in-house accounting and tax professionals in MNEs, we find a limited use of IT for automating transfer price setting as well as documenting compliance with the arm's length principle. That said, some degree of automation is observed in regards to the intra-organizational workflow management of producing documentation files. The overall low level of IT automation observed is grounded in both system-level arguments, e.g. fragmented accounting information system (AIS) environments, as well as in-house functional hierarchies. Specifically, management accountants and IT functions are found to dominate the AIS design agenda, while the tax function's goals of transfer pricing tax compliance plays a relatively marginal role. We argue that while MNE tax functions have gained increasing attention among MNE top executives in the wake of BEPS, management accountants and IT experts continue to play a superior role in the design of internal accounting and reporting systems. Ultimately, this limits the tax function's ability to fully automate the transfer pricing process, partially because the accounting and system configurations prioritized by management accountants and IT staff often conflict with those system designs preferred for managing transfer pricing tax risks.
\end{abstract} pricing, multinational enterprises, intra-organizational power, functional hierarchies 


\section{Introduction}

This paper studies the extent to which multinational enterprises use information technology (IT) for automating international transfer pricing (ITP). Specifically, we study the use of IT and automation in the context of price setting and documentation in accordance with the arm's length principle set forth in global tax regulation ${ }^{1}$.

International transfer pricing continues to receive massive attention from scholars in the areas of management accounting and control. Recent work has demonstrated how MNEs have started to shift their accounting practices for ITP towards a more tax compliance-oriented agenda (e.g. Cools et al., 2008: Klassen et al., 2017; EY 2019; Hummel et al., 2019), abandoning the rather aggressive tax agenda that previously dominated MNE tax strategies (Hanlon and Heizman, 2010). One of the reasons for this shift in tax risk appetite among MNEs stems from a continuous effort among prominent trade institutions e.g. the European Union and OECD to reduce alleged tax avoidance. Particularly, the OECD and their recent action plan on base erosion and profit shifting (BEPS) represents an unprecedented tax regulatory shock that has gained significant attention among MNE top managers and their tax functions. This action plan was initiated by OECD in 2013 based on G20 leaders' push for a supra-national initiative to mitigate alleged tax avoidance in MNEs. The final reports (OECD, 2015) that emerged from the action plan addressed a variety of accounting and tax items that directly or indirectly were considered levers of tax avoidance. This includes new comprehensive transfer pricing guidelines for setting transfer prices and to document that they are in accordance with the arm's length principle (OECD, 2017).

\footnotetext{
${ }^{1}$ Operational ITP involves two main tasks: a) setting transfer prices for intra-group cross-border transactions based on the arm's length principle, and b) producing documentation to tax authorities that demonstrates compliance with the arm's length principle.
} 
Given the tightened tax regulatory requirements facing MNEs, combined with increased attention to tax digitization (EY, 2017) among MNE tax functions, the issue of IT and automation in context of ITP takes on increased importance. A recent stream of empirical research in management accounting and control has contributed to the understanding of the way MNEs respond to tax regulation, particularly the effect on management control system design and use. For example, Cools et al. (2008) demonstrated the way implementation of a tax compliance strategy has significant impact on management controls, e.g. budgeting and performance measurement. Other case-based studies have explored the impact of ITP and tax compliance on management control systems in MNEs (e.g. Cools et al., 2008; Cools and Slagmulder, 2009; Plesner Rossing, 2013). However, the relationship between ITP and accounting information systems (AISs) has received surprisingly limited attention, including to which degree MNEs utilize IT to automate the tax risk management of ITP. More specifically, neither management control research, nor the AIS literature, offer insights into the degree to which MNEs depend on technology for pricing and documentation of intra-group transactions to meet tax regulatory requirements. For example, the degree to which MNE tax functions rely on manual processes and Excel-spreadsheet solutions to manage ITP is unclear. At the same time, accounting and tax service providers, such as Big 4 accounting firms, continue to market various ITP software applications towards MNEs, which seem to suggest some degree of MNE attraction to such tools. However, the actual degree of MNE adoption and motives for implementation (or rejection) of these tools remains opaque. In fact, AIS research seems to disregard tax strategic objectives within contemporary accounting systems of MNEs entirely, despite MNEs reporting that tax risks and ITP is receiving unprecedented attention within their organizations (e.g. EY, 2016, 2019; Klassen et al., 2017). Therefore, we formulate the following research question as our primary topic of 
analysis: How are multinational enterprises using information technology for managing international transfer pricing?

We contribute to a recent stream of contingency theory-based literature in accounting where researchers engage in direct interactions with tax and transfer pricing managers in MNEs, in order to enhance the understanding of how these organizations work to adapt to their tax regulatory requirements (Cools et al., 2008; Cools and Slagmulder; Hasseldine et al., 2011; Mulligan and Oats, 2009, 2016; Plesner Rossing, 2013; Rogers and Oats, 2019). Based on 21 interviews conducted between August 2018 and January 2019 (i.e. post-BEPS) with in-house accounting and tax professionals in MNEs, we find a limited use of IT for automating transfer price setting as well as documenting compliance with the arm's length principle. That said, some degree of automation is observed in regards to the intra-organizational workflow management to produce local documentation files in accordance with the new BEPS requirements ${ }^{2}$. The overall low level of IT use observed is grounded in system-level arguments, e.g. fragmented accounting information system (AIS) environments, but also driven by functional hierarchies and intraorganizational power configurations. Specifically, management accountants and IT functions are found to dominate the AIS design agenda, while the tax function's goals of transfer pricing tax compliance plays a relatively marginal role. We argue that while MNE tax functions have gained increasing attention among MNE top executives in the wake of BEPS, management accountants and IT experts continue to play a superior role in the design of internal accounting and reporting systems. This ultimately limits the tax function's ability to fully automate the transfer pricing process, mainly because the accounting and system configurations prioritized by management

\footnotetext{
${ }^{2}$ The new OECD Guidelines (OECD, 2017) Chapter V requires MNEs to produce transfer pricing documentation files for those local business entities involved in inter-company transactions, to demonstrate compliance with the arm's length principle.
} 
accountants and IT staff often conflict with those system designs preferred for managing transfer pricing tax risks.

The remainder of the paper is organized as follows: Section 2 presents the literature review and theoretical guidance. Section 3 presents the research strategy and design. Section 4 presents the empirical findings and section 5 discusses these observations.

\section{Literature review and theoretical guidance}

\section{Transfer pricing literature}

Transfer pricing has direct impact on management control systems in both domestic and multinational organizations as it impacts the entire accounting cycle from planning and budgeting to the ex post measurement of sub unit and individual managers' performance (Merchant and van der Steede, 2017; Zimmerman, 2020). Initial research on transfer pricing focused on the way transfer pricing needed to be optimized for the purpose of efficient resource allocation (e.g. Hirshleifer, 1956) while ensuring integration between diversified units (Watson and Baumler, 1975; Colbert and Spicer, 1995, van der Meer Kooistra, 1994). As globalization increased the tax dimension of transfer pricing started to receive attention from tax policy makers looking to mitigate alleged tax evasion. At the same time academics from various domains, including tax law, accounting and economics began confirming widespread tax avoidance through transfer pricing (Clausing 2001, 2003; Harris 1993) typically based on quantitative data obtained from public financial databases or corporate tax returns, see Hanlon and Heitzman (2010) for a review.

Another stream of empirical literature, typically applying contingency theory as the underlying theoretical frame, identifies structural variables for the design of MNE transfer pricing systems (e.g. Borkowski, 1990, 1992ab, 1996; Emmanuel and Mehafdi, 1994). Using survey 
instruments as the typical data collection method this literature identifies relationships between e.g. certain organizational structures, and conditions and choice of transfer pricing methods (cost, market, negotiated prices), as well as the managerial priorities and strategic objectives of transfer pricing decisions (e.g. Cravens, 1997; Cravens and Shearon, 1996). A more recent stream of qualitative research (e.g. Cools et al., 2008; Cools and Slagmulder, 2009; Plesner Rossing; 2013) have expanded initial findings within the contingency school of ITP research, demonstrating the way case studies are valuable for understanding the multi-faceted dynamics in play within MNEs as they seek to fulfill ITP objectives. Cools et al. (2008) found that a tax compliance strategy has a direct impact on MCSs, including planning, budgeting, and performance measurement. In a similar vein Cools and Slagmulder (2009) showed that ITP policies essentially require a redesign of responsibility accounting structures in MNEs, including a conversion of cost centers into pseudo-profit centers to adhere to tax regulatory arm's length requirements. Plesner Rossing (2013) illustrated the way interactive controls are used to refine ITP strategies in a dynamic and highly uncertain tax environment.

Current research generally finds a significant shift in MNE tax strategic objectives, as previous aggressive tax avoidance agendas appears to have been substituted by more compliancebased tax agendas (e.g. Klassen et al., 2017; Mulligan and Oats, 2009, 2016; Cools et al., 2008; Rossing, 2013; Hummel et al., 2019). This seems to be not only driven by technical tax risks, e.g. double taxation but also due to the consideration of reputational risks (Auston and Wilson, 2017). Overall, academic contributions (Wunder, 2009) as well as professional surveys (EY, 2016, 2019) point to that the management of tax risks continues to be a top priority of transfer pricing in MNEs. Yet the MNE tax functions' use of technology in context of ITP tax risks remains a black box. This includes a limited understanding of the way MNE tax departments interact with other key 
functions of accounting and IT. In this context, the role of management accountants have been heavily debated in the accounting literature for decades, including their transition from bean counters into roles as strategic business partners for operational management in organizations (Shields, 1997; Byrne and Pierce, 2007; Horton and Wanderley 2018). As part of this transition, it is evident that management accountants play a key role in collaboration with in-house IT staff to ensure that AIS designs provide a basis for organizations to achieve commercial goals (Granlund, 2011; Grabski, Leech and Schmidt 2011; Rikhardson and Yigitbasioglu 2018). Hence, the increasingly important tax objectives in MNEs handled by in-house tax specialists creates a basis for increased interaction - and possible frictions - between these in-house professional groups, i.e. management accountants, IT specialists, tax managers, that warrants further investigation.

\section{Automation of accounting}

Accounting and IT is considered in a variety of literature streams, with the vast majority of research residing in the AIS domain. The literature tends to apply a functionalistic approach, examining e.g. contingent factors of IT and ERP system adoption, design, and functionality. Parts of the literature have sought to advance understanding of the different pressures that emerge over time within and outside organizations to drive adoption and subsequent increase in AIS sophistication. For example, Kung et al., (2015) examined technology complexity using a taxonomy of mimetic, coercive and normative pressures. Specifically, mimetic pressures stem from isomorphic incentives to imitate peer organizations' technology systems and IT environments. Coercive pressures refer to pressures for technological adoption or reconfigurations from organizations upon which the adopter is dependent. Normative pressures involve forces of a 
more formalized nature, e.g. from professional standards or those emerging from professional communities within which an organization exist.

Other parts of the academic literature have studied the impact of ERP systems on organizational decision making and control, emphasizing the importance of recognizing the people-component as a basis for explaining organizational practices and human behavior (Kocsis 2019). As part of this individual-focused agenda, Henri (2006) noted the importance of understanding cultural variation across organizations in order to enhance performance management system design and facilitate managerial decision making. Other researchers have focused on the role of management accountants in processes of information system change (Malmi and Granlund, 2009; Granlund and Malmi, 2002; Quattrone and Hopper, 2005; Jack and Koleif, 2008; Byrne and Pierce, 2007). Chapman notes the theoretical potential of ERP system research going beyond "technological curiosities" (p. 685) to explore and answer more fundamentally issues of management control. Along these lines, earlier work by Bariff and Galbraith (1978) suggested that the political significance of organizational reporting systems should be explicitly recognized in information system research. This includes the powerful coalition between organizational accountants and information system experts who control the administration and distribution of organizational information through AIS and ERP applications.

However, despite an active AIS research agenda recognizing that all aspects of accounting data collection is impacted by technology (Arnold, 2016) and in some cases is controlled by technology (Sutton et al., 2016), research on the automation of accounting remains surprisingly limited. In fact, Kocsis (2019) reviewed current AIS research and noted that while accounting professionals are seeing automation and artificial intelligence take over auditing and control, the academic literature does not seem to reflect this empirical reality: "Automation only appears a few 
times in the [reviewed] articles, as does artificial intelligence" (page 8). Specially in the context of transfer pricing, Taipaleenmäki and Ikäheimo (2013) conceptualize the recent convergence of management accounting and financial accounting with the advancements in IT, noting that: "Within the technical and technological domain, recent developments in activities, such as financial reporting and stock market regulation, voluntary disclosures, performance measurement, transfer pricing, competitor, customer and contractor analysis, as well as due diligence in M\&A activities, all contain major converging elements in which IT plays an important, even pivotal role." (p. 343).

Notwithstanding the widespread recognition among academics as well as tax professionals of the inherent role of technology in MNE tax risk management, only a few contributions have been made to advance our understanding of MNE perspectives on IT and tax automation. An example is Gallemore and Labro (2015) who find that firms with high-quality internal information environment have lower and less volatile cash ETRs relative to other firms. Similar, Hamilton and Stekelberg (2017) find that firms with high-quality IT are able to achieve lower as well as more stable cash effective tax rates than are other firms. However, to our knowledge no existing research explores to which degree MNE tax departments use technology for managing tax risks in general, and for ITP in particularly. This include research that interacts with the in-house accounting and tax managers responsible for implementing MNE tax strategies. In response, we study MNE tax departments' use of IT in the context of ITP. We focus on the two main tasks of operational ITP: implementation of the ITP policy (price setting) and the subsequent development of documentation files to demonstrate regulatory compliance with the arm's length principle. We examine two potential contingent factors of ITP automation: system-level drivers e.g. ERP system design, and individual-level drivers e.g. tax department managers' promotion or rejection of ITP automation 
tools. Hence, we use contingency theory as our theoretical basis of analysis, and the MNE tax department is our level of analysis. Figure 1 illustrates our guiding framework for the empirical analysis.

\section{Figure 1. Guiding framework}

Context variable

Tax regulatory environment

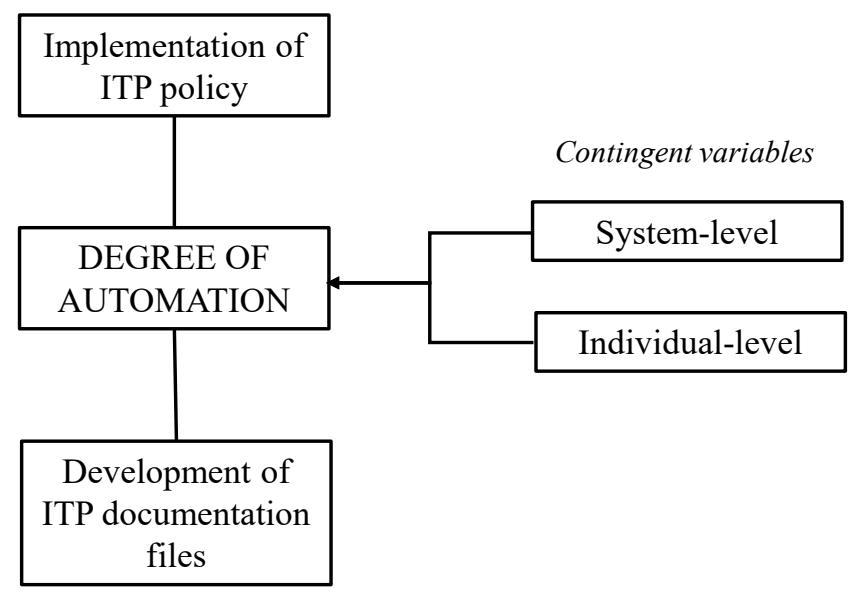

\section{Research Strategy and Design}

Due to the limited understanding of how MNEs use IT and automation for managing transfer pricing tax risks, a qualitative research approach was applied. As emphasized by Yin (2018) 'how' and 'why' questions can be answered through qualitative research designs where the researcher interacts directly with the research object under study. Theoretical sampling (Eisenhardt, 1989) was used for selecting in-house accounting and tax experts in MNEs with a broad global presence. Furthermore, the MNEs involved needed to be vertically integrated to 
ensure that they were exposed to significant transfer pricing tax risks. Also, to ensure a common tax regulatory/tax political context, the MNEs needed to be headquartered in Germany.

This qualitative study focus on $20 \operatorname{large}^{3}$ MNEs with operations in a variety of different industries. The MNEs included in this study are based in Germany, except one which is based on the US ${ }^{4}$. The data was collected between August 2018 and January 2019 as part of a broader study on ITP and tax risk management in MNEs. Hence, our data entails not only key details on ITP in context of AIS and IT, but also a variety of contextual information of general ITP and tax risk management for the MNEs under study. Furthermore, the timing of the data collection allows us to make novel inferences regarding MNEs' perspectives and responses on the OECD's BEPS initiative. The 20 MNEs under study were selected as they all are involved in high volumes of inter-company cross-border transactions that must be managed for tax purposes, and inherently interacts with the ERP system(s) within their respective organizations. These MNEs are subject to current and unprecedented tax regulatory dynamics introduced from supra-national institution, e.g. OECD and EU. At the same time, German-based MNEs are under significant pressure from the German tax authorities who enforces a rigorous transfer pricing regulatory framework in accordance with the OECD Guidelines and the arm's length principle ${ }^{5}$ In fact, EY's transfer pricing survey reveals that Germany - according to survey respondents - was the nation where transfer pricing policies have most often faced official examinations (EY 2016, p. 18) creating a suitable context for our study.

\footnotetext{
${ }^{3}$ https://ec.europa.eu/eurostat/web/structural-business-statistics/structural-business-statistics/sme

${ }^{4}$ This MNE used to be a German-based MNE but was acquired by a foreign investor before the data collection took place. The MNE maintained its previous ITP system and the data obtained from this organization is considered useful for the purpose of this study.

${ }^{5}$ Germany is a member of the OECD and generally adhere to the arm's length principle and OECD Guidelines. https://www.oecd.org/tax/transfer-pricing/transfer-pricing-country-profile-germany.pdf
} 
Our analysis draw on a variety of data sources. Our main data input comes from 21 interviews with 25 in-house accounting and tax professionals ${ }^{6}$. These respondents were carefully selected as they have either direct ITP responsibility or at least functional involvement with ITP as part of their professional duties. Table 1 provides insights to MNE and interviewee characteristics.

Table 1. MNE and interviewee characteristics

\begin{tabular}{|c|c|c|c|c|c|}
\hline MNEs & MNE S & yenue ( & ns EUR) & $\Sigma$ & $\Sigma$ \\
\hline Sectors & $<1$ & $<10$ & $>10$ & MNEs & Interviews \\
\hline Mechanical and Plant Engineering & 1 & 7 & 1 & 9 & 9 \\
\hline Pharmaceutical Industry & & & 3 & 3 & 3 \\
\hline Consumer Goods Industry & & & 1 & 1 & 1 \\
\hline Retail and Wholesale & & 4 & & 4 & 4 \\
\hline Industrial Conglomerate & & & 1 & 1 & 2 \\
\hline Manufacturer Household Appliances & & 1 & & 1 & 1 \\
\hline Manufacturer Electrical Material & 1 & & & 1 & 1 \\
\hline Total & 2 & 12 & 6 & 20 & 21 \\
\hline
\end{tabular}

\begin{tabular}{|lcc|c|}
\hline INTERVIEWEES & Headquarters & Subsidiary & $\Sigma$ \\
\hline TP manager & 16 & 1 & 17 \\
Tax director & 5 & 0 & 5 \\
Internal auditor & 1 & 0 & 1 \\
Controller & 0 & 2 & 2 \\
\hline Total & 22 & 3 & 25 \\
\hline
\end{tabular}

All interviews besides one were recorded and transcribed. For the unrecorded interview, details notes were taken during and immediately after the interview to reduce recollection bias. The interviews were semi-structured to ensure some degree of structure in the conversations while at the same time allowing respondents to touch upon ITP issues that were specific to their industry or in other ways unique to their organizational context. The interview guide was informed by

\footnotetext{
${ }^{6}$ Two interviews had two participants; one interview had three participants.
} 
current research findings within ITP literature. Furthermore, a partner from a Big Four accounting firm assisted in the development of the interview guide by providing inputs to ensure that it was contemporary and balanced in context of the theoretical and practical ITP issues facing large MNEs in the wake of recent tax regulatory disruptions such as BEPS. Finally, one of the researchers participated in a two-day network group meeting with in-house tax and ITP professionals to gain further insights to the ITP issues they are dealing with in the current tax environment. The interview guide was refined over time based on the feedback provided. The main interview themes included in the interview guide were 'tax risk appetite', 'perspectives on BEPS', 'IT and software tools used for ITP', 'operational management of ITP', 'impact of ITP on management controls', 'use of inter and intra-organizational networks for ITP management'; 'influence of internal variables' (i.e. organizational structure, business strategy etc.), and impact from external/context variables (tax regulatory environments, practices of tax authorities, etc.).

Prior to the actual interviews conducted by one of the researchers, the MNE websites were reviewed to ensure a sufficient degree of commercial understanding of the MNE in question. This helped fine-tune the individual interviews as well as assisted in the subsequent discussions for the purpose of data analysis. Furthermore, a variety of publicly available documents from commercial vendors presenting ITP software were reviewed, including its intended functionalities and application for the purpose of ITP automation in MNEs ${ }^{7}$. These vendors are typically Big four accounting firms or other boutique ITP service providers offering ITP automation tools.

Interviews were coded in MAXQDA using a detailed coding scheme. The coding scheme was initially based on the interview guide and the guiding framework in Figure 1. Subsequent codes were added as the coding process and initial analysis of data progressed with unexpected

\footnotetext{
${ }^{7}$ The paper neither praise nor condemn any specific ITP/tax software product or tax service provider.
} 
and novel trends emerging from the data. Notably, coding is an important step in organizing data but does not in itself represent a complete analysis of such data. Rather, the coding assisted us in structuring the data vis-a-vis specific themes of interest as well as identify preliminary trends in the data, from where more critical data analyses and conclusions were derived. This includes extraction of quotes that were deemed appropriate for capturing e.g. specific perceptions of ITP automation or preferences for more manual data processing solutions, as well as tensions between specific organizational functions important for understanding the full scope of factors impacting the degree of IT and automation used for ITP. Finally, we developed a thematic matrix based on the guidance by Miles and Huberman (2019) which not only assisted us in our preliminary analysis but also serve as the basis for our summary of findings in Table 2.

\section{Findings}

\subsection{The MNE tax function}

The MNEs examined in this study have all been subject to increased attention from global tax authorities in recent years. Moreover, MNE boards and C-suite level executives have started to interact more directly with the in-house tax functions around tax governance practices and the tax risk management strategies, including those tied to ITP. Interviewees noted in particularly the way BEPS has created massive disruption among their respective MNEs and resulted in more explicit attention from top managers on the activities performed by the MNE tax functions:

"This is high risk and therefore high value. They know BEPS, they have heard from their network, forums and their advisers. Therefore they come to us and ask how do we handle it? That is actually also why you see BEPS everywhere in the compliance guideline, because it is a game changer [...] It is not only bad. It has giving us so much work and a lot of it is really interesting work. For instance the value chain analysis that is making sure that we do that. It is actually a good thing that the tax professional understand what drives the value in the group." (INT 9) 
"Our Chief Financial Officer is well acquainted with the subject. Not in all its facets, of course, but he understands the interrelationships and naturally discusses it with his colleagues from affiliated companies and with representatives from the political scene."(INT 25)

"The more transfer prices are discussed in public, the more important the topic becomes in the levels where C-level is located and the more relevant transfer prices become in the company."(INT 24)

Generally, the tax function of the MNEs under study is formally located as a sub-function underneath the main finance function in charge of group-level accounting, reporting and compliance. The tax function typically has international responsibility for direct and indirect taxes, including ITP:

"There is the Finance Division. This is the roof. Under it, there are different pillars [...] Then there are one or two smaller areas, namely the Planning and Controlling and Taxes and Customs. And that is where we move with the transfer price group."(INT 25)

The MNE tax functions were found to be extremely centralized - a phenomenon that was further accelerated by BEPS to ensure rigorous tax department control of ITP - and only in rare cases were dedicated tax people located at the subsidiary level. The tax departments' main operational ITP responsibility involves determining arm's length budget targets and ensure ongoing internal achievement of these, as well as develop subsequent documentation that transfer prices and their contractual circumstances adhere to the arm's length principle. Also, ad hoc ITP tasks handled by the tax department involves providing support during local tax audits subject to ITP scrutiny as well as completing advance pricing agreement $\left(\mathrm{APA}^{8}\right)$ negotiations with tax authorities.

Top managements' attention to ITP appears to be focused on the strategic importance of shaping a tone at the top to convey the tax risk appetite to the in-house operational staff at the tax

\footnotetext{
${ }^{8} \mathrm{An}$ APA is a contractual arrangement where specific MNE legal entities and tax authorities agree on ex ante transfer pricing policies, including choice of ITP method and/or pre-tax earnings margins for the entities included in the agreement.
} 
department in charge of operationalization and implementation. While top managers were generally well aware of the themes addressed in the BEPS final reports, they did not seem to possess deep technical insights to the specific implication for ITP in context of their MNE value chains. However, an increasing interest among top managers in regards to tax departments' activities and responsibilities had emerged, including a switch from 'tax' being a decentralized compliance exercise de facto receiving no active top management attention, to an 'open-door' policy:

"Since BEPS, the door at the board of directors is always open for us. [...] In the past, the topic (ITP) was still viewed very negatively and we only did what was necessary to meet the legal requirements. This has now changed." (INT 6)

As part of the transition towards implementing tax strategies for ITP in accordance with BEPS requirements and other tax regulatory initiatives, the vast majority of MNEs had considered some degree of automation for price setting and documentation. Generally, these tools extract data out of different ERP systems to create a harmonized data base. Specifically, these ITP tools can either be used through software solution that integrates with popular ERP system packages or as add-on software that interacts and extract data from the core ERP modules. Key functionalities promoted by the external vendors vis-a-vis the ITP price setting phase are the automated creation of segmented P\&Ls and dashboard-based margin monitoring, as well as scenario features to simulate profit margin effects from specific ITP policies. For the documentation phase, the tools typically offer pre-build text narratives to describe legal entity functionalities (manufacturing, distribution, etc.). Several tools also offer work flow modules intended to assist MNE tax functions with controlling inputs from key individuals (controllers, subsidiary finance managers, etc.) who need to provide inputs for completion of the local documentation files. Section 4.2 and 4.3 consider 
the way the MNEs under study perceive these tools and the degree to which they are used for managing price setting and documentation for ITP.

\subsection{ITP automation: Setting transfer prices}

The MNEs studied apply different organizational structures, and the degrees of vertical integration varies in accordance with commercial strategies and operational priorities. However, the German headquarter can generally be viewed as the main entrepreneur of the group, assuming the significant business risks and owning several of the key intangible assets driving the commercial activities. In contrast, subsidiaries generally perform relatively less risky business functions, in many cases activities of a more routine nature such as manufacturing, distribution, logistics etc. However, to ensure operational as well as tax efficiency in subsidiaries where more sophisticated (risky) commercial activities occur, and due to historic acquisitions of IP intensive subsidiaries, the group's intangible assets are not always owned and maintained by the German parent:

"For example, if we had acquisitions and the acquired company that had some kind of IP, which happened to be in a low-tax country, then the IP was left there. Which then led to us having a lot of IP owners..." (INT 11)

The main intra-group transactions observed are the transfers of physical goods and services. The physical good transactions involves mainly the core manufacturing products, and services includes a wide variety of administrative services. In addition, the use of intangible property through different formats of intra-group licensing arrangements were emphasized by several interviewees:

"The most important cross-border supply and service relationships are, on the one hand, the material goods transactions, i.e. physical goods transactions in the various divisions of a company. Then there are IP-related transactions, i.e. a licensing system between affiliated companies. And then the third major area is the 
clearing of services between affiliated companies, which is then split up into various subcategories."(INT 25)

The standard approach observed for ITP price setting is one where the tax department at headquarters develops a group transfer pricing policy in cooperation with top management, primarily the CFO who typically assumes ultimate tax responsibility. The centralization of ITP is important to ensure a consistent approach across the group. Hence, while subsidiary managers provide important commercial/transactional information to the tax department in Germany, they generally have limited influence on the formal policy design. The policy typically describes basic objectives of ITP, methods applied to certain intra-group transactions etc. However, it was clear from the interviewees that the tax department is heavily dependent on other administrative functions in order to ensure successful implementation of the specific ITP price setting policy throughout the value chain. Particularly the accounting function and the in-house IT specialists were emphasized as they are directly in charge of handling the actual implementation of the policy, including making sure that the ITP method selected by the tax department is applied to specific intra-group transactions:

"...The determination of transfer prices, and I should say the determination of profit margins for transfer prices, is the exclusive responsibility of the tax department, and that is where our colleagues from IT and controlling are also the recipients of information and implement the things that come from the tax department."(INT 25)

"Systemic conversion takes place in SAP. This means we (tax department) pass information to colleagues in the shared service centers, who then enter this information in the accounting organization so that prices can be calculated correctly."(INT 25)

According to interviewees, the main issue of the ITP price setting exercise, which has significant implications for the ability to automate this process, is to ensure useful data segmentation. As the tax department need to document the arm's length nature of specific intra- 
group transactions at the end of the reporting period based on ex post accounting data, appropriate segmentation of intra-group transactions in the ERP system is crucial.

"...we actually want to define certain data that we need from the individual SAP ERP systems of the various companies [...] this is the only way to determine, for example, the segmented income statement."(INT 8)

We observe a number of limitations in the tax departments' ability to enforce this tax compliance driven agenda vis-à-vis the ERP system segmentation. Generally, interviewees agreed that while ITP has moved up on the strategic agenda of top managers, particular post-BEPS, the tax department's ability to influence the ERP system design and facilitate a segmentation format that conforms to the data needs for tax compliance seems rather limited. Instead, the ERP system design decisions are generally made by the management accountants and IT specialists to ensure general systemic control and rigor, and ensure the ability to make ERP system extract that satisfies the commercial management reporting needs of business executives:

"...the IT solution already exists, but the question is interface programming, because it is of course also the case and our IT, our own in-house IT sets high standards. If you as a specialist (tax) department intervene in the ERP system yourself, then of course this is a very critical, very business-critical step." (INT 25)

"...we have to acknowledge that tax is not the center of the world. We follow business, business does not follow us." (INT 9)

With regards to this issue of segmentation, the formats needed for management reporting are found to be different from those needed for tax compliance. One reason is that the tax compliance segmentation typically needs to happen at the intra-group transactional level, and from there an aggregation needs to take place, typically at the legal entity level. Conversely, the management reporting is developed based on the need for commercial decision making without 
explicit attention to tax compliance. This includes accounting practices that not necessarily are aligned to the tax department's objectives and rationales. For example, the management accountants perform cost allocations strictly for business decision making and reporting purposes, whereas from the tax department's perspective, there can be very direct inefficiencies from this, e.g. double taxation:

"...it is indeed the case that there is a field of tension between controlling and the tax department in the sense that controlling is often interested in a very detailed, cause-related cost allocation and thus also allocation. This applies in particular to services. In the case of material goods, there are normally not so many problems, but in the case of intercompany service allocation, it is often the case that from the point of view of Controlling, an allocation is necessary and the Tax Department or the transfer price team may then have to say: "No, we can't do that so easily. Or it is not possible with this country. We can indeed offset, but then these are nondeductible business expenses. "(INT 25)

A related issue that seemed to have limited the enthusiasm among respondents for price setting automation is the fact that the MNEs typically apply a wide variety of different ERP systems. One reason for these fragmented ERP environments is past mergers and acquisitions where the acquired company's ERP platform is continued. Such fragmented ERP structures create a barrier for automation as the tax department would need to invest seemingly disproportionate time and efforts into having several ERP platforms re-configured and standardized throughout the value chain in order to implement an automated ITP solution:

“...we do not use SAP for transfer pricing purposes. It would be nice but it does not make sense here because the IT landscape is so fragmented." (INT 9)

"In my view, the basic prerequisites for the transfer pricing process to be integrated into tax operations would be the standardization of ERP systems, which is not the case in all of our countries at present" (INT 16)

"If you really want to do it IT-based, where you only have to push a button, you first of all need a uniform ERP system, otherwise you have an extremely high effort."(INT 1) 
“... a heterogeneous SAP landscape, that's where it starts" (INT 10)

However, this does not mean that MNEs consider ITP automation solely an issue of ensuring more structure and uniformity in the ERP platform alone. Rather, several interviewees noted the importance of having a greater degree of standardization in the ITP landscape throughout the MNE value chain. In fact, the standardization of ITP seemed to be considered a pre-condition for ITP automation to even be a realistic scenario:

“As soon as we can standardize, we can start automate."(INT 9)

"The simpler the transfer pricing system, the better it can be automated. If you have a transfer pricing system with a thousand exceptions, then in theory you can still automate it, but it is difficult." (INT 11)

Interviewees generally seem to be intrigued by the theoretical idea of ITP automation, and some were actually in an experimental phase of automating the pricing of specific intra-group transactions. This was perceived to be long-term and costly projects, subject to significant uncertainty in light of the aforementioned structural and systemic limitations:

"We are also talking about a period of probably ten years for implementation." (INT 16)

Hence, some degree of skepticism seemed to be present even among the 'pro-automation' interviewees. Also, these in-process automation solutions seemed to be limited in scope, versus a fully-automated solution where the entire price setting and ongoing profit margin adjustments would occur automatically throughout the year. Particularly, different add-on software solutions related to ex post diagnostic margin controlling throughout the year was observed. The main perceived benefits of these tools appear to be the tax department's ability to handle in real-time cases where the management accountants did not succeed in implementing the ITP policy that was conveyed by the tax department at the outset of the annual accounting cycle. Some interviewees noted that while the arm's length policy to guide intra-group invoicing was formalized at the 
beginning of the year, including arm's length pre-tax target margins for the subsidiaries, they would often experience significant variance from targets when reviewing the end-of-period (monthly quarterly, annual) results:

"If you had detailed planning for the entities, then you could check during the year with margin-oriented transfer pricing methods whether I am heading in the right direction. [...] Then you could ideally make adjustment entries during the year and not only at the end of the year. This would mean less discussion during the tax audits. There are already these cases where the budget values you offset against are not correct, and then there is, for example, another double offsetting at the end of the year. Then, of course, every auditor comes and asks, "What is this, why is this so? Is it really based on arm's length data or not?" That's always a topic of discussion." (INT 24)

For those tax departments that were found to use monitoring tools to enhance their realtime arm's length-based diagnostic controlling, these tools are typically not integrated with the ERP system. Instead, they are 'add-on' software solutions that sit on top of the core ERP system and pull data from the relevant ERP modules. The tax department can subsequently process these extracts to assess the degree of periodic adherence to arm's length earnings targets as well as forecast for the individual subsidiaries:

"... with the help of this system, forecast values can also be determined for the profit margins, so to speak, which can then be applied for the following quarters on a certain observation date[...] it gets data from SAP. This data is imported separately, but we then report the calculation result back to our colleagues, so to speak, who then enter it into the (SAP) system via appropriate interfaces." (INT 8)

Still, these solutions are not integrated in a way that allows for full ITP automation, including an automated journal entry adjustment within the relevant ERP module. Hence, manual assessment and data processing, e.g. using Microsoft Excel applications, were still necessary as a basis for developing inputs to controllers and their subsequent journal entry adjustments in SAP: 
"...the calculation process and simulation process itself is all done in Excel."

(INT 1)

The general ITP automation vision for these MNEs seems to be a solution where SAP can handle the implementation of the ITP policy. However, for some MNEs it is not only a matter of automating the policy-based price setting process. Also, the ability to perform real-time simulations were emphasized as a key factor. This includes particularly the ability to directly simulate pre- and post-tax effects from potential changes to transfer prices for specific transactions. ${ }^{9}$ An interviewee currently involved in an ITP automation project commented: "....so you can imagine, we have different SAP systems in use, different ones. And from these systems it should be possible to import the individual tables from the financial, controlling and materials management data into the uniform Business Warehouse, where it will be possible to monitor and adjust the margins in a permanent manner. And of course, we also imagine that modulation calculations can be made on this basis. What will change if we modify a parameter for a specific country in a specific transfer pricing transaction? Then it can immediately calculate down what the effects will be. Then you can include the tax rate and so on. This is what we envision for the IT system at the end of the project." (INT 9)

In context of ITP automation there seems to be a limitation among some respondents as to how much influence they actually want to have on the ERP system. Specifically, certain in-house tax professionals actually are comfortable with playing a more limited role where the scope of their ITP-based controlling responsibility does not create an unrealistic burden or distort the relatively more important commercially-based controlling and data analytics that takes place throughout the MNE group:

"And we also have to think carefully about this from the tax department, how much responsibility we can take, how much we want to take with us, how our resources are at that point, because that is always my example or my position here, which I represent in the company. We cannot build up a second controlling department with

\footnotetext{
${ }^{9}$ Such analysis would for example be relevant e.g. under a TNMM methodological approach to test whether relevant earnings margins falls too far from a benchmark median value or similar measure of comparability.
} 
our capacities in the tax department. That is simply not possible. There are only a handful of people who deal with transfer pricing in the company, but hundreds, if not thousands of colleagues who deal with business analytics or controlling. And we cannot, so to speak, saddle up on that. We can't do that. You just have to work together and the tax department has to think about what it is able to achieve with the human resources it has." (INT 25)

In addition, while the aforementioned systemic/structural limitations mentioned seem to be the key drivers of the limited degree of ITP automation observed, also factors at the individual level were observed. Specifically, it appears that current in-house tax resources are indeed comfortable with more 'traditional' domains of tax compliance, e.g. corporate tax law, accounting, finance, etc. However, they apparently have relatively limited skills in IT and seem to have some degree of reluctance towards getting directly involved in the somewhat unfamiliar territory of IT in general and automation in particular:

"I see all tax departments if they want to be perceived doing the right thing they have to work more with IT. This scares a lot of tax professionals because many of them are tax nerds. They do not like IT and they do not understand IT. I actually look forward to the new generation of the so called tax technologist. The guys who understand tax from a structured perspective and who are able to squeeze that in an IT system. This is what we will see. It is stressed for the last couple of years and it will be bigger and bigger. We need more IT systems and automation because our compliance burden will increase and we will not get more people. That is the direction."(INT 9)

Along these lines, an interviewee conveyed the decision to make recruitment decisions in the attempt to improve the configuration of the tax department's human resources to the growing tax automation agenda. This had proven beneficial as the multi-level understanding of core tax regulatory conditions combined with IT skills had created valuable synergies to leverage ITP policies through collaboration with controllers and in-house IT personnel. Notably, it appears that there is an important generational factor at play here as the younger staff who currently take on 
entry-level positons with tax departments have a greater sense and level of confidence in technology to support more modern tax and ITP workflows:

"I have people in my team who not only have an understanding of tax law, but also have knowledge of the systems, SAP and other IT-based systems. The whole department becomes much more technical. We are now reaching a technical level that the controlling department has had for years. This is a good development.[...] Maybe it's also due to the low average age (in the tax department), that people there are more open for such topics. " (INT 24)

Other interviewees stressed the importance of IT knowledge within the tax department, including the need for tax department human resources taking more responsibility to work directly with IT and system applications to facilitate the achievement of tax objectives:

"Well, the requirements would be such that we would say that IT knowledge is definitely an advantage. There must also be an IT affinity. In other words, the willingness to work a lot with systems. In transfer pricing, you can't just rely on saying: "I'm working on the topic from a legal perspective." In other words, very closely focused on the legal regulations, working closely with the law. The system or the topic of transfer pricing is too practice-oriented and also too business management oriented for that. Knowledge of business administration is definitely required, but if you take these major areas of focus - business administration and controlling on the one hand and IT on the other, if you see them as a kind of headline, then these could well be people who represent very different disciplines from their studies and have different backgrounds. "(INT 25)

As part of this increased recognition that IT is a critical part of the agenda of the ITP tax department, an interviewee stressed how the managerial attention to tax at the outset of an ITP automation agenda can play an important role for assessing the opportunities and potential of automating the tax department activities. This includes the ability of tax department resources in bridging tax knowledge with in-depth insights and technical expertise on the MNE's IT infrastructure.

"So there is certainly a lot to be achieved through learning by doing or training on the job. We are in the fortunate position that the head of the tax department recognized many years ago that IT is an important topic in the tax field. And he 
himself also has a very high IT affinity for taxes, not only in terms of transfer prices, so that he brought a colleague from IT into the tax department many years ago as the responsible manager, with whom I also work very closely. He is also part of the transfer pricing team, but only part-time, because he is also responsible for the IT infrastructure, the IT landscape for the tax department. And of course that helps a lot. It helps immensely because he has a very deep technical knowledge of IT. But on the other hand, through his work in the tax department, he also has a profound knowledge of what can be implemented and how things can be implemented in IT."'(INT 25)

\subsection{ITP Automation: Documenting transfer prices}

The MNEs under study are subject to increased documentation requirements both in Germany and abroad. The main effect stems from global tax authorities implementing the results of Action 13 in the BEPS Action plan. The formal result of Action 13 is the introduction of a master/local file documentation approach, accompanied by a country-by-country report to assist tax authorities in their risk assessment of individual MNEs. The master file seems to cause limited issues for the MNEs as this file contains more holistic and general descriptive information on the MNE value chain that can rather easily be developed. In contrast, the local files now requires much more detailed information and explanations of specific intra-group transactions and the MNE subentities involved in order to justify ITP practices. The MNEs generally handle the documentation in-house but use local consultants to ensure that documentation outputs are aligned to specific domestic tax compliance requirements:

"We do that (documentation) in-house. Consultants are very little involved with us because we have a very large tax department with almost 40 people worldwide." (INT INotably, the documentation exercise does not happen detached from the initial price setting. Rather, it is found to be deeply integrated with the price setting as the documentation essentially requires justifying the arm's length nature of transfer prices that have been applied to specific transactions throughout 
the annual accounting cycle. Given that transfer price setting is deeply integrated in the ERP systems, in order for the tax department to process the documentation requirements they are forced to interact closely with the relevant ERP and IT systems to extract and re-organize the accounting data:

“...in my opinion, transfer pricing is $80 \%$ IT, because I have to crystallize the transaction, I have to know how it was calculated, what margins are involved. In other words, very IT-intensive in my opinion. "(INT 6)

While we generally observe a very low degree of automation for the price setting across the MNEs, there is a more widespread use of the automation tools for ITP documentation. This include a generally more positive attitude from interviewees on how these tools can assist the tax department on the documentation task. Notably, the lack of automation in the transfer price setting creates a systemic barrier for the degree of data automation that can be introduced for the documentation task (due to the aforementioned task inter-dependencies). Hence given the limited price setting automation, only limited automation such as data importing from the ERP system directly into the documentation files was observed. Instead, a rather time consuming and error prone manual documentation process was continued post-BEPS. That said, one of the popular features among the MNEs actually using the documentation tools relates to the fact that the tools typically offer different kinds of pre-narrated text modules that MNEs can customize to their specific commercial facts and circumstances. Several MNEs were intrigued by these tools and have already implemented them or are actively planning to do this. One of the main reasons emphasized is that the tools can help to enhance the degree of standardization in the formatting of the documentation reports:

"We have a layout, the [MNE name] Local File always looks the same, the structure is always the same, so that we know afterwards where to find what information." (INT 13) 
Several MNEs had in the past developed much more fragmented and poorly aligned documentation files in specific jurisdictions, making it difficult to review and update the files. By using the tool, the pre-developed text modules from the tool can be used to set up the local files in a more consistent manner as well as revise them as needed, typically by involving a local consultant to make adjustments to local documentation rules. Notably, BEPS seemed to be a key driver in switching from the more manual 'loose-leaf' type of documentation approach to a more standardized and rigorous format using the documentation software tools:

"We are currently in the process of introducing a new tool, which takes a much more centralized approach. Where we centrally issue transfer pricing templates from the tax department. Where we describe our main transactions, in coordination with the business. We also do centralized competition and industry analyses, which we all feed centrally into this tool and actually tell the group companies that this is your basic framework in terms of content. "Please take a local consultant, who will only adapt the local content to your needs." (INT 13)

"The best example is the documentation tool, which has simply not been an issue for us up to now. Before that we had a collection of sheets of paper which have been accepted by the German tax authorities in this format. We can no longer continue to use this format after BEPS and either we do everything manually, which is extremely time-consuming, especially if you want to harmonize internationally, or we buy a tool and set up a reasonable process, also with the business divisions. This was definitely initiated by BEPS. I personally see this as a great advantage." (INT 1)

"We provide the building blocks and documentation elements centrally, so that our colleagues do not have to think about how to formulate the content or design the texts. Instead, we provide a document framework and qualitative and quantitative information flows into this document framework, which the local colleagues can then contribute from their local systems and with their knowledge of the local conditions" (INT 25)

Some MNEs were even planning on making the use of the tool mandatory for the local subsidiaries. This was perceived to enhance not only the consistency in documentation outputs but also the efficiency in producing and updating the annual documentation files: 
"Actually we want to get to the point where a local file is printed out from this tool worldwide. We will also make this mandatory, they [subsidiaries] are not allowed to do it any other way." (INT 13)

"What is important for us, if I now abstract from the individual business group, is harmonization [...] the process must develop in such a way that we don't create TP documentation in every country as we have done up to now, and then hand it in.[...] especially now with the new situation with the masterfile, which has to or should be uniform anyway, it's hard enough to get it to work, but the local files have to be coordinated as well and the processes have to develop towards getting away from this island documentation and towards a group documentation."(INT 1)

"We have the manpower that we can actually do more and we did a project last year, where we created templates for the most important transactions, for documentation templates, which we will use for the German companies, but which we will also give to the foreign companies. And now, in principle, we have also established a process, which is already in place, it has not yet been approved by the Board of Management, but by the decisive, let's say, middle management divisions and [company] CFO and so on, they have already agreed. What counts is that the local companies must basically work with our templates and produce annual documentation, unless this is somehow a sales ruse, which can also be done every three years, which is also sufficient as long as they are not locally obliged to do it annually. In this respect, we work with templates, but we are only just in the process of getting rid of this really seriously." (INT 11)

Part of the benefit of increased consistency in local files is the ability to present homogenous documentation files across jurisdictions where the functional profile of the legal entities is considered similar. Given that global tax authorities are increasingly exchanging information to assess the consistency in ITP practices of individual MNE entities, having a consistent and efficient documentation approach seemed to be an important value driver in considering, and in some cases, actively using the ITP tools:

"Ideally, our templates will of course improve from year to year, because we intend to review and adapt them, but so does an auditor in Spain, who perhaps also talks to an Italian auditor, who says that they can, for example, lay the transfer price documentation of both units next to each other and say, well, exactly the same thing here. So that is our vision, I would say."(INT 13) 
“...we are currently converting them (documentation files) based on BEPS. Up to now it was rather a loose-leaf collection, now we really build up a consistent documentation, which is then used uniformly everywhere. Currently we are still doing it in [Microsoft] Word, but we are in the process of introducing a tool that will take the work off our shoulders and keep the whole thing consistent. At the moment, whenever we submit a local file somewhere, we have to check manually that it is consistent with other local files. This is of course incredibly timeconsuming." (INT 1)

Notably, some of these tools do not only offer pre-build text narratives for the documentation files that can be used when local subsidiary controllers and the centralized tax department collaborate to develop documentation files. They also have integrated workflow modules that facilitate the tax department's workflow management of developing ITP documentation. For example, one feature of this is the ability to manage the timing of specific actions and communication between key in-house professionals to ensure that necessary actions are taken in due course, e.g. automated emails at certain points in time. The centralized tax departments generally seem to recognize that local controllers and finance managers are involved in many tasks aside from tax compliance that need prioritized. Hence, the tool is valuable in facilitating an organized planning and workflow schedule, with active communication to meet tax compliance deadlines during busy subsidiary-level work schedules:

"What we actually done is to buy a system that ensures for example automatic emails that request people to do something actively. This is something that will be big in the next couple of years because this is how to push the (documentation) processes to life. I am positive but it won't be easy. To be honest we are not asking to do more, we are only asking to do it more structured. Sometimes it is difficult for some people when they work in the year-end closing period or the budget faces. If they work 60 hours a week, it is difficult to squeeze in transfer pricing compliance, but we are focusing on the periods they are not so busy and make sure that they do it consistently."(INT 9) 
Other interviewees have explored these documentation tools in demo formats but seems to be discouraged by the perceived significant resources that needs devoted to customize and maintain such tools:

"We once looked at an online documentation tool that automatically generates documentation from the text modules [...] I think that it is also extremely timeconsuming to maintain." (INT 22)

An additional issue that caused reduced interest among some interviewees was that the tools are not perceived to adapt sufficiently to the local documentation requirements. This means that a local consultant still needs to be engaged in order to make sure that the final documentation file is compliant with local rules and formalities:

“...we still had a local consultant who created transfer pricing documentation in addition to our tool, because the documentation, which was tool-based, did not meet local requirements [...] every country has its own specific requirements. Then you would have to modify the tool a lot" (INT 13)

Generally, we observed a more pro-automation attitude for ITP documentation than for price setting. Specifically, most of the MNEs are either strongly considering automating the development of the documentation files including the process workflows, or are actively involved in projects to implement various automation tools to facilitate this agenda. An interesting observation in context of this generally pro-automation agenda is that while the BEPS project seems to have significantly increased the attention from top management on the activities of the tax department, the allocation of resources to deal with BEPS documentation requirements do not seem to be that well aligned. In context of this, it appears that for some MNEs, the deliberations on whether to convert from a manual documentation approach towards a more automated documentation process is not only driven by the fundamental appeal of automation. Rather there appears to be a more urgent need for automation in order to ensure that scarce tax department human resources can be still be allocated to other non-ITP tasks: 
“...at least in our company, a shift from capacity allocation for tax planning activities to capacity allocation for greater compliance is simply taking place. Simply because we cannot divide ourselves and if the capacities remain relatively stable but the compliance expenditure becomes higher, we also have to make several resources necessarily available for the compliance activities and simply try to create again free capacity by a stronger automation or digitalization in order to be able to implement tax planning projects." (INT 25)

\section{Concluding discussion}

In this paper we studied MNE use of IT for managing transfer pricing tax risks, including to which degree they have automated their ITP processes to ensure compliance with the arm's length principle. Table 2 organizes the main findings from our empirical analysis.

Table 2. Use of information technology for ITP 


\begin{tabular}{|c|c|c|}
\hline & Price setting & Documentation \\
\hline $\begin{array}{l}\text { General } \\
\text { observations on } \\
\text { the use of IT }\end{array}$ & $\begin{array}{l}\text { - Limited use of information } \\
\text { technology for automating price } \\
\text { setting } \\
\text { Limited integrated systems } \\
\text { observed to enable automation and } \\
\text { central margin monitoring. } \\
\text { - Interviewees generally skeptical } \\
\text { that full ITP automation is } \\
\text { realistic. } \\
\text { - Some MNEs have invested in a } \\
\text { price setting tool enabling } \\
\text { segmented P\&Ls, margin } \\
\text { monitoring, and simulation of } \\
\text { segment-level profit margins } \\
\text { - Significant use of manual data } \\
\text { processing observed, including } \\
\text { Excel-based processing of } \\
\text { accounting data } \\
\text { Due to increasing legal } \\
\text { requirements, manual processes } \\
\text { become more error-prone and } \\
\text { time-consuming }\end{array}$ & $\begin{array}{l}\text { - Limited use of information technology } \\
\text { for automation. However, ITP } \\
\text { processes for documentation are more } \\
\text { automated than for ITP price setting. } \\
\text { Limited automation is observed, mainly } \\
\text { due to AIS/ERP data segmentation not } \\
\text { being aligned with ITP reporting needs. } \\
\text { BEPS is driving a need for a more } \\
\text { consistent documentation setup, e.g. } \\
\text { group-wide consistency in } \\
\text { documentation files. } \\
\text { To enhance consistency in } \\
\text { documentation files, a more } \\
\text { standardized approach is observed. } \\
\text { This includes centralized creation of } \\
\text { standard/pre-narrated templates for } \\
\text { local files. In such cases, external } \\
\text { documentation software is often used. } \\
\text { External documentation software used } \\
\text { not only supports documentation file } \\
\text { content - it also assist the workflow } \\
\text { management of documentation file } \\
\text { development. }\end{array}$ \\
\hline $\begin{array}{l}\text { General } \\
\text { observations on } \\
\text { functional } \\
\text { hierarchies }\end{array}$ & \multicolumn{2}{|c|}{$\begin{array}{l}\text { Tax departments are subject to increased organizational awareness, } \\
\text { particularly from top management teams. They are mainly responsible for } \\
\text { TPS design (i.e. publishing a TP policy, supervising transfer pricing } \\
\text { process). } \\
\text { Tax departments play a more subordinate role vis-à-vis the more powerful } \\
\text { management accountants and in-house IT experts, limiting their ability to } \\
\text { automate ITP. }\end{array}$} \\
\hline
\end{tabular}




\begin{tabular}{|c|c|c|}
\hline & Price setting & Documentation \\
\hline $\begin{array}{l}\text { Organizational- } \\
\text { level variables } \\
\text { (structural/system- } \\
\text { level) }\end{array}$ & $\begin{array}{l}\text { - AIS/ERP system fragmentation } \\
\text { significantly reduces the use of } \\
\text { information technology } \\
\text { - } \text { Only a few MNEs in the initial } \\
\text { phase of costly long-term ITP } \\
\text { automation projects. ERP system } \\
\text { harmonization projects. } \\
\text { - ERP system design authorized by } \\
\text { management accountants and IT } \\
\text { staff. } \\
\text { - ERP system designs based on } \\
\text { internal information and reporting } \\
\text { objectives as defined by the } \\
\text { management accountants/IT } \\
\text { function - not the tax function } \\
\text { Conflicting ERP design needs } \\
\text { (segmentation) between tax } \\
\text { function and management } \\
\text { accountants. The objectives of } \\
\text { management accountants and IT } \\
\text { experts take priority over tax } \\
\text { goals. } \\
\text { Group-wide standardization of } \\
\text { ITP practices is perceived a pre- } \\
\text { requirement before automation } \\
\text { can take place. } \\
\text { - Price setting tools are not } \\
\text { integrated in the ERP system } \\
\text { Price setting tools are too } \\
\text { expensive and need complex } \\
\text { implementation projects } \\
\text { IT tools are not always convincing } \\
\text { enough }\end{array}$ & $\begin{array}{l}\text { - ERP system fragmentation reduces the } \\
\text { basis for automation (i.e. data for } \\
\text { documentation dependent on legal- } \\
\text { entity data segmentation) } \\
\text { - ITP documentation tools are not } \\
\text { creating automated documentations, } \\
\text { they "only" support the coordination of } \\
\text { the process } \\
\text { - ITP documentation tools in some cases } \\
\text { considered too time consuming and } \\
\text { expensive by MNEs } \\
\text { - Consultants are used to modify and } \\
\text { reach local documentation } \\
\text { requirements }\end{array}$ \\
\hline $\begin{array}{l}\text { Individual-level } \\
\text { variables }\end{array}$ & $\begin{array}{l}\text { Tax function managers concerned } \\
\text { with taking on too much } \\
\text { responsibility for AIS design. This } \\
\text { includes the risk of building a } \\
\text { second controlling function. } \\
\text { - Tax function managers are } \\
\text { traditionally not IT experts and } \\
\text { generally uncomfortable with } \\
\text { tax/ITP technology. } \\
\text { The importance of IT for ITP is } \\
\text { generally recognized, with some } \\
\text { MNEs actively looking to employ } \\
\text { IT-skilled human resources. }\end{array}$ & $\begin{array}{l}\text { Tax function not highly automated but } \\
\text { tax/ITP managers envision more } \\
\text { automation for documentation going } \\
\text { forward. } \\
\text { - Some of the IT enthusiasm observed is } \\
\text { driven by the lack of resources post- } \\
\text { BEPS, causing pressure of tax function } \\
\text { human resources. }\end{array}$ \\
\hline
\end{tabular}


In regards to implementation of the ITP policy, i.e. transfer price setting, we found a low degree of IT use and an overall widespread skepticism towards ITP automation. While 'automation' has theoretical appeal among our interviewees, the AIS configurations in MNEs create a variety of barriers and complications for ITP automation. Notably, these barriers are located at both the organizational level (structural/system-level barriers) as well as resistance grounded in more individual-level conditions. At the organizational level, the main barrier observed relates to the high degree of fragmentation in ERP platforms across the MNEs studied. This structural condition prevents the tax departments' ability to control and monitor the price setting process during the fiscal year. Furthermore, while there are serval external tools on the market which are able to extract data from popular ERP solutions, these tools are perceived to be very costly and typically have to be implemented in the context of elaborate and complex IT projects, ultimately limiting their appeal among the MNEs studied. Moreover, while we echo recent observations that MNE tax departments are subject to increased organizational attention (Cools et al., 2008; Mulligan and Oats, 2009, 2016; Plesner Rossing, 2013), we find that they still play a more subordinate role visà-vis the more powerful management accountants and in-house IT experts who are the ultimate decisions makers on AIS designs. A particular issue here is the fact that AIS system designs, driven by the management accountants and IT experts, is found to be based on the need for internal management reporting with ITP and tax compliance being more of a secondary objective. Specifically, the lack of alignment between the segmentation needed for these two objectives, i.e. ITP tax compliance driven by transactional reporting per legal entity versus the need for management reporting subject to other (non-tax regulatory) segmentation priorities and information needs, creates a significant barrier for ITP automation. Ultimately, this causes tax departments to gravitate towards traditional Excel applications for the management of transfer 
pricing tax risks. In contrast, for the production of subsequent documentation files to support the end-of-year tax return filings and demonstrate arm's length compliance, the degree of automation and positive attitude towards the external ITP tools available seems to be more widespread. However, we observe that the automation is more grounded in process and workflow management for getting the documentation files produced in a timely and consistent manner across the subsidiaries. Furthermore, external ITP tools offering standardized templates of the local files, including pre-developed narratives for functional analyses etc., were used by several MNEs. Nevertheless, the process of accounting data generation (e.g. imports to documentation files from ERP cost modules) is primarily manual. Hence, also for the documentation task, Excel and other more manual, error-prone and time-consuming system applications are widespread with little direct automation of pulling accounting data into the documentation files by use of ITP automation software.

We also observed a number of individual-level barriers of ITP automation. Specifically, it seems that while the MNE tax department generally is subject to increased organizational visibility, there is still some degree of reluctance among in-house tax professionals to get deeply involved in the technical AIS domain. Tax professionals are found to be highly capable of the legal aspect of ITP. Yet, it seems that, traditionally, there has not been a strong focus in MNE tax departments on the pivotal role of AIS, including the direct integration of IT in the management of transfer pricing tax risks. The MNEs studied have started to recognize more the importance of IT, particularly in the wake of BEPS. This includes the need to reconfigure in-house tax function by adapting recruitment strategies and employ human resources with strong(er) IT capabilities. In addition, there is a resistance among some MNEs to automate ITP due to the perceived risk of creating a 'shadow' controlling function. The MNE tax departments generally seem to believe that 
they are not capable of handling a massive controlling/business analytics function that interacts and potentially intrude - with other more primary objectives of commercial control and management reporting carried out by the management accountants.

In context of Kung et al's (2015) taxonomy of mimetic, coercive and normative pressures, we find that the (limited) degree of ITP automation observed appears mainly driven by the need for less manual data processing and workflow management. The recent BEPS project - in particular the revision to OECD Guidelines Chapter V on ITP documentation - seems to have created massive pressure on the MNE tax department resources. While we find that managements' attention to ITP has increased, it is somewhat surprising to observe that the tax departments' resources do not seem to follow. Specifically, MNEs currently find themselves in need of automating the documentation tasks to enhance efficiency and consistency in the production of local files. The main reason being the need to free up scarce human resources to handle other tasks e.g. the continuous manual processing of ITP policy implementation as well as other tax function activities. Hence, while automation is by no means required within the OECD Guidelines, the normative pressure from BEPS seems to be the main driver of ITP automation. There is also an additional, although seemingly more secondary, awareness of ITP automation among some interviewees caused by the intense promotion of ITP software tools from external ITP consultants. However, MNEs seem less receptive to consultants' push for automation, mainly due to the aforementioned structural/system-based limitations.

Our findings also contribute to research into the role of management accountants (Shields, 1997; Byrne and Pierce, 2007; Horton and Wanderley 2018) as we demonstrate their extensive power vis-à-vis the tax executives in MNEs. Again, while MNE tax departments have significantly increased their standing within the organizational hierarchy of MNEs, and are increasingly 
involved real-time in strategic decision making, they still play only a secondary role in decisions around AIS and ERP design. We echo the notion that management accountants play a key role in collaboration with in-house IT staff to ensure that AIS designs provide a basis for organizations to achieve strategic goals (Granlund, 2011; Grabski, Leech and Schmidt 2011; Richardson and Yigitbasioglu 2018), and add that this powerful standing exists at the expense of other - more secondary - tax objectives in MNEs.

Looking ahead we question whether ITP automation will materialize to an extensive degree. Several of the systemic barriers observed appears de facto permanent in nature (e.g. fragmentation in ERP systems), and the powerful role of management accountants and IT experts vis-à-vis the in-house tax function seem unlikely to change. We speculate that only a more formal tax regulatory demand for automation will have a material effect as tax compliant MNEs will have no choice but to allow at least some degree of tax function influence on AIS design and reporting configurations. Needless to say, this will require a more material push throughout the organizational level of operations from top managers (boards, CFOs, etc.) as our findings clearly show a tax function - while being more visible than before - still playing a subordinate role in the context of AIS/ERP configurations. 


\section{REFERENCES}

Abernethy, M. A. and Vagnoni, E. 2004. Power, Organization Design and Managerial Behavior, Accounting, Organization and Society 29 (3/4): 207-225.

Arnold, V. 2016. The changing technological environment and the future of behavioural research in accounting. Accounting \& Finance 58 (2): 315-339.

Austin, C. R., and R. J. Wilson. 2017. An Examination of Reputational Costs and Tax Avoidance: Evidence from Firms with Valuable Consumer Brands. Journal of the American Taxation Association 39 (1): 67-93.

Bariff, M. L., and J. Galbraith. 1978. Intraorganizational power considerations for designing information systems. Accounting, Organizations and Society 3 (1): 15-27.

Borkowski, S. C. 1990. Environmental and organizational factors affecting transfer pricing: A survey. Journal of Management Accounting Research 1990 (Fall): 78-99.

Borkowski, S. C. 1992a. Organizational and international factors affecting multinational transfer pricing. Advances in International Accounting 5: 173-192.

Borkowski, S. C. 1992b. Choosing a transfer pricing method: A study of the domestic and international decision-making process. Journal of International Accounting, Auditing and Taxation: $33-49$.

Borkowski, S. C. 1996. An analysis (meta- and otherwise) of multinational transfer pricing research. The International Journal of Accounting 31 (1): 39-53.

Byrne, S. M., and B. Pierce. 2007. Towards a More Comprehensive Understanding of the Roles of Management Accountants. European Accounting Review 16 (3): 469-498.

Byrne, S., and B. Pierce. 2007. Towards a More Comprehensive Understanding of the Roles of Management Accountants. European Accounting Review 16 (3): 469-498.

Clausing, K. A. 2001. The Impact of Transfer Pricing on Intrafirm Trade. In Hines J. R. (Ed.), International Taxation and Multinational Activity. University of Chicago Press, Chicago: 173-194.

Clausing, K. A. 2003. Tax-motivated transfer pricing and US intrafirm trade prices. Journal of Public Economics 87 (9): 2207-2223.

Colbert, G. J., and B. H. Spicer. 1995. A multi-case investigation of a theory of the transfer pricing process. Accounting, Organizations and Society 20 (6): 423-456. 
Cools, M., and R. Slagmulder. 2009. Tax-compliant transfer pricing and responsibility accounting. Journal of Management Accounting Research 21 (1): 151-178.

Cools, M., C. Emmanuel, and A. Jorissen. 2008. Management control in the transfer pricing tax compliant multinational enterprise. Accounting, Organizations and Society 33 (6): 603-628.

Cravens, K. 1997. Examining the role of transfer pricing as a strategy for multinational firms. International Business Review 6 (2): 127-145.

Cravens, K., and W. T. Shearon. 1996. An outcome-based assessment of international transfer pricing policy. The International Journal of Accounting 31 (4): 419-443.

Emmanuel, C. R., and M. Mehafdi. 1994. Transfer pricing. London: Academic Press Ltd.

Eisenhardt, K. M.1989. Building Theories from Case Study Research. Academy of Management Review 14(4): 532-550.

EY. 2016. 2016 Transfer Pricing Survey Series. In the Spotlight: A new era of transparency and risk. EYGM Limited.

EY. 2017. Tax technology and transformation: Tax functions 'go digital'. Ernst \& Young LLP: India.

EY. 2019. 2019 Transfer Pricing and International Tax Survey. EYGM Limited.

Gallemore, J., and E. Labro. 2015. The importance of the internal information environment for tax avoidance. Journal of Accounting and Economics 60 (1): 149-167.

Grabski, S. V., S. A. Leech, and P. J. Schmidt. 2011. A Review of ERP Research: A Future Agenda for Accounting Information Systems. Journal of Information Systems 25 (1): $37-78$.

Granlund, M. 2011. Extending AIS research to management accounting and control issues: A research note. International Journal of Accounting Information System 12 (1): 3-19.

Granlund, M., and T. Malmi. 2002. Moderate impact of ERPS on management accounting: a lag or permanent outcome? Management Accounting Research 13 (3): 299-321.

Hamilton, R., and J. Stekelberg. 2017. The effect of high-quality information technology on corporate tax avoidance and tax risk. Journal of Information Systems 31 (2): 83-106.

Hanlon, M., and S. Heitzman. 2010. A review of tax research. Journal of Accounting and Economics 50: 127-178. 
Harris, D. G. 1993. The Impact of US Tax Law Revision on Multinational Corporations' Capital Location and Income-Shifting Decisions. Journal of Accounting Research 31: 111-140.

Hasseldine J., K. Holland, and P. van der Rijt. 2011. The market for corporate tax knowledge. Critical perspectives on Accounting 22 (1): 39-52.

Hirshleifer, J. 1956. On the Economics of Transfer Pricing. The Journal of Business 29: 172.

Horton, K. E., and C. Wanderley. Identity conflict and the paradox of embedded agency in the management accounting profession: Adding a new piece to the theoretical jigsaw. Management Accounting Research 38 (March): 39-50.

Hummel, K., D. Pfaff, and B. Bisig. 2019. Can the integration of a tax-compliant transfer pricing system into the management control system be successful? Yes, it can! Journal of Accounting \& Organizational Change 15 (2): 198-230.

Jack, L., and A. Kholeif. 2008. Enterprise Resource Planning and a contest to limit the role of management accountants: A strong structuration perspective. Accounting Forum 32 (1): $30-45$.

Klassen, K. J., P. Lisowsky, and D. Mescall. 2017. Transfer pricing: Strategies, practices, and tax minimization. Contemporary Accounting Research 34 (1): 455-493.

Kocsis, D. 2019. A conceptual foundation of design and implementation research in accounting information systems. International Journal of Accounting Information Systems 34: 1-10.

Kung, L., C. G. Cegielski, and H. Kung. 2015. An Integrated Environmental Perspective on Software as a Service Adoption in Manufacturing and Retail Firms. Journal of Information Technology 30 (4).

Malmi, T., and M. Granlund. 2009. In Search of Management Accounting Theory. European Accounting Review 18 (3): 597-620.

Merchant, K., and W. van der Stede. 2017. Management control systems: performance measurement, evaluation, and incentives. Fourth edition. Harlow: Pearson.

Miles, M. B., Huberman, A. M., and Saldana, J. 2019. Qualitative Data Analysis: A Methods Source Book, 4. Fourth edition. Los Angeles. SAGE.

Mulligan, E., and L. Oats. 2009. Tax Risk Management: Evidence from the United States. British Tax Review 6: 680-703.

Mulligan, E., and L. Oats. 2016. Tax professionals at work in Silicon Valley. Accounting, Organizations and Society 52 (July): 63-76. 
Organisation for Economic Co-Operation and Development (OECD). 2015. BEPS 2015 Final Reports. OECD: Paris.

Organisation for Economic Co-Operation and Development (OECD). 2017. Transfer Pricing Guidelines for Multinational Enterprises and Tax Administrations. Paris: OECD.

Plesner Rossing, C. 2013. Tax strategy control: The case of transfer pricing tax risk management. Management Accounting Research 24 (2): 175-194.

Quattrone, P., and T. Hopper. 2005. A 'time-space odyssey': management control systems in two multinational organisations. Accounting, Organizations and Society 30: 735-764.

Rikhardson, P., and O. Yigitbasioglu. 2018. Business intelligence \& analytics in management accounting research: Status and future focus. International Journal of Accounting Information Systems 29 (June): 37-58.

Rogers, H., and L. Oats. 2019. Emerging Perspectives on the Evolving Arm's Length Principle and Formulary Apportionment. British Tax Review 2: 150-165.

Schaltegger, S., and Zvezdov, D. 2015. Gatekeepers of Sustainability Information: Exploring the Roles of Accountants. Journal of Accounting \& Organizational Change 11 (3): 333-361.

Shields M. D. 1997. Research in Management Accounting by North Americans in the 1990s. Journal of Management Accounting Research (9): 3-61.

Sutton, S., M. Holt, and V. Arnold. 2016. "The reports of my death are greatly exaggerated" Artificial intelligence research in accounting. International Journal of Accounting Information Systems 22 (issue C): 60-73.

Taipaleenmäki, J., and S. Ikäheimo. 2013. On the convergence of management accounting and financial accounting - the role of information technology in accounting change. International Journal of Accounting Information Systems 14 (4): 321-348.

Van der Meer-Kooistra, J. 1994. The coordination of internal transactions: The functioning of transfer pricing systems in the organizational context. Management Accounting Research 5 (2): 123-152.

Watson, D. J., and J. V. Baumler. 1975. Transfer Pricing: A Behavioral Context. The Accounting Review 50 (3): 466-474.

Wunder, H. F. 2009. Tax risk management and the multinational enterprise. Journal of International Accounting Auditing and Taxation 18 (1): 14-28.

Yin, R. K. 2018. Case Study Research and Applications: Design and Methods. Sixth edition. Los Angeles. Sage. 
Zimmerman, J. 2020. Accounting for decision making and control. Tenth edition. New York, NY: McGraw-Hill Education. 